\title{
Short-Term Application of Chitosan Coated Mg-1Zn-0.3Zr-2Gd-1Ca Alloy Bone Implants in Osteoporotic Fractures
}

\section{Zhanhui Wang ${ }^{1 *}$, Yawei Li" ${ }^{1 \#, ~ Z o n g b i n ~ S u n ', ~ J i u b a ~ W e n ², ~ B i n g b i n g ~ Z h a n g 1 ', ~ T i n g h e ~ D u a n ', ~}$ Qiuxia Zheng ${ }^{3}$ and Shaopeng Liu'}

${ }^{1}$ Luoyang Central Hospital, Zhengzhou University, China

${ }^{2}$ School of Material Engineering, Henan University of Science and Technology, China

${ }^{3}$ The Second Affiliated Hospital of Zhengzhou University, China

\#Equal contribution

\begin{abstract}
With the rapid aging of the global population, osteoporosis seriously affects human life and health, and the most serious clinical manifestation is osteoporosis fracture. Therefore, biomedical workers have been investing a lot of research on biomedical materials in the treatment of osteoporotic fracture. The aim of this research is to assess the biodegradability and biocompatibility of chitosan-coated Mg-1Zn-0.3Zr-2Gd-1Ca alloy as bone screws, and to explore the feasibility of the chitosan coated Mg-1Zn-0.3Zr-2Gd-1Ca alloy in the treatment of osteoporotic fractures. In this study, the uncoated Mg-1Zn-0.3Zr-2Gd-1Ca alloy screws and chitosan-coated $\mathrm{Mg}-1 \mathrm{Zn}-0.3 \mathrm{Zr}-2 \mathrm{Gd}-1 \mathrm{Ca}$ alloy screws were implanted into the fracture sites of rats, respectively. Then the $\mathrm{X}$-ray changes of the operation areas were observe that different times. The degradation behavior of bone screws was evaluated for by scanning electron microscopy (SEM) and energy dispersion spectrum (EDS). The bio-safety of the Mg-1Zn- $0.3 \mathrm{Zr}$ $2 \mathrm{Gd}-1 \mathrm{Ca}$ alloy to rat liver and kidney tissues were determined by eosin staining, and the $\mathrm{Mg}$ and $\mathrm{Ca}$ ions levels in peripheral blood were measured. The postoperative vital signs were stable and no surgical complications were observed. X-ray images showed that both bare group and chitosan group had good fixation after surgery. Inflammatory exudation could be seen in all groups. However, SEM results showed the implants in chitosan group had less corrosion rate than that of in bare group with a complete structure. The main elements of degradation products in bare group and chitosan were $\mathrm{Mg}, \mathrm{O}, \mathrm{Ca}$, and $\mathrm{Zn}$ as shown by EDS analysis. Histopathological and serological tests showed that there was no significant toxicity of chitosan coated bone nails on SD rats. Chitosan coated Mg-1Zn-0.3Zr-2Gd-1Ca alloy could not only effectively retard the degradation rate of $\mathrm{Mg}-1 \mathrm{Zn}-0.3 \mathrm{Zr}-2 \mathrm{Gd}-1 \mathrm{Ca}$ alloys in rats but had good biocompatibility in rats, which was more favorable for fracture repair and suggested its possible clinical application.
\end{abstract}

Keywords

Osteoporotic fracture, Magnesium alloy, Chitosan coating, Biodegradability, Biocompatibility

*Corresponding author: Dr. Zhanhui Wang, Department of Surgery, The Affiliated Luoyang Central Hospital, Zhengzhou University, 288 Zhongzhou Road, Luoyang, 471000, China, Tel: +86-379-6389-2095, Fax: +86-379-6389-2095

Accepted: August 01, 2020; Published: August 03, 2020

Copyright: (c) 2020 Wang Z, et al. This is an open-access article distributed under the terms of the Creative Commons Attribution License, which permits unrestricted use, distribution, and reproduction in any medium, provided the original author and source are credited.

Wang et al. Int J Metall Met Phys 2020, 5:057 


\section{Introduction}

Osteoporosis is a kind of bone disease characterized by the decrease of bone mechanical strength and the increase of fracture risk. The prevalence of osteoporosis has increased for the last few years, and the incidence of fractures has also increased. Internal fixation of biomaterials is one of the most important treatments for fractures [1]. It is common knowledge that excellent fracture internal fixation materials should have good biocompatibility, biodegradation properties consistent with bone repair, good mechanical strength, and plasticity. Nowadays, internal fixation materials can be divided into biomedical polymer materials, biomedical inorganic non-metal materials, and biomedical metal materials $[2,3]$.

As to the materials for the therapy of diseases, the invention of biomedical metal materials has broadened the selectivity of fracture fixation materials. Cobalt-chromium (Co-Cl) alloys, titanium ( $\mathrm{Ti}$ ) alloys, and memory alloys have been widely used in clinical practice due to their good biocompatibility and corrosion resistance [4-6]. However, the elastic modulus of these materials is much higher than the elastic modulus of bone tissue, and this may be one of the factors inducing re-fracture according to the stress shielding effect $[7,8]$. What is more, it has to be removed by a second operation because of its' long-term retention causing extra trauma to patient.

Degradable metal materials such as $\mathrm{Mg}$ and its alloy in recent years, due to their good biocompatibility, mechanical properties, and degradability, were studied for the applications in the field of orthopaedic devices or cardiovascular stents [9-11]. A review by Frank Witte reported that an eightyear-old child with a humerus fracture was fixed by $\mathrm{Mg}$ plate and screw through operation, and the $\mathrm{Mg}$ plate had almost completely degraded at 3 weeks after the operation with the fracture line disappearing. Moreover, magnesium alloy as bone fixation could stimulate bone growth and healing [10]. In addition to the above characteristics, $\mathrm{Mg}$ and its alloy also have good biomechanical properties. It is related to the fact that the elastic modulus and compressive strength of $\mathrm{Mg}$ alloys are closer to those of natural bone [12]. However, their excessive corrosion rates in humans and the resulting stress corrosion cracking properties seriously affect the $\mathrm{Mg}$ alloy application range [13-22]. Therefore, one or more additional alloys are under investigation in order to improve their properties. Among above materials, zinc ( $\mathrm{Zn}$ ) and calcium (Ca) are common element $[13,23,24]$; in addition, it was reported that Ca plays a vital role in fracture healing $[25,26]$. Some researches showed that $\mathrm{Zr}$ not only has good biocompatibility, but also can improve the corrosion resistance and biomechanical properties of magnesium alloy [12]. Therefore, alloy is used in this study as a fixator of fracture.

Fractures are a common occurrence and can be classified into traumatic fractures, osteoporotic fractures, etc [27]. Osteoporosis fracture, as its name implies, is a pathological fracture caused by osteoporosis, which endangers human health [28]. Internal fixation is one of the most important surgical treatments for osteoporotic fracture. There are many kinds of internal fixation materials, including Mg-Ca alloys, $\mathrm{Zn}$ alloy, and Ti alloys [29]. Among them, the current most clinically applied alloy is the Mg-Ca alloy. However, the Mg content on the earth is rich, and $\mathrm{Mg}, \mathrm{Zn}, \mathrm{Ca}$ ions are essential trace elements of the human body, which play important roles in the body's metabolism and fracture healing process. Related studies $[30,31]$ reported that the application of metallic $\mathrm{Mg}$ as an internal fixation material to the femur of the rat promoted the formation of new bone tissue around the fracture area, thereby promoting fracture healing. Chitosan can be used as a biomaterial with good biocompatibility, good plasticity, and low toxicity after modification, and shows good application value [32,33]. However, there are few studies on the application of chitosan coating in $\mathrm{Mg}$-Ca alloys for internal fixation of fractures. Therefore, the role of this new $\mathrm{Mg}-1 \mathrm{Zn}-0.3 \mathrm{Zr}-2 \mathrm{Gd}-1 \mathrm{Ca}$ alloy in the treatment of osteoporotic fracture in rats was studied.

Generally, in order to improve the corrosion resistance and biological compatibility of magnesium alloy, many measures have been taken to improve the surface of magnesium alloy matrix, such as inorganic coatings $[9,34]$, biodegradable polymers [35], etc. Chitosan, as a cationic polymer, has been studied as a pharmaceutical component by many researchers because of its good biodegradability, biosafety and mucoadhesive. Thus, in this study a new chitosan-coated Mg-1Zn-0.3Zr-2Gd-1Ca alloy nail was prepared, and its biodegradation behavior and biosafety behavior of were explored in the treatment of osteoporotic fractures for rat model 
in order to design a new Mg alloy bone nail that can overcome defects of traditional bone nail made of non-absorbable materials.

\section{Experimental Methods}

\section{Preparation of chitosan-coated Mg alloy}

Mg-Ga alloy was prepared using a vacuum smelting resistance furnace (ZG JL0.01-40-4, Jinzhou transformer furnace factory of Liaoning Province). The Mg-1Zn-0.3 Zr-2Gd-1Ca alloy (from the College of Materials, Henan University of Science and Technology) was prepared according to their different burn loss amounts in different proportions, and was dissolved in a tungsten crucible under argon protection, with heat preservation at $480{ }^{\circ} \mathrm{C}$ for 20 min. The metal elements were mixed thoroughly with a graphite rod, followed by refining, slagging, and staging. In the vacuum smelting resistance furnace, the $\mathrm{Mg}$ alloy solution at $420^{\circ} \mathrm{C}$ was poured into an iron crucible with a preheating temperature of $200{ }^{\circ} \mathrm{C}$, and then release after $30 \mathrm{~min}$, to obtain the casting sample. The test chamber temperature was increased to $300{ }^{\circ} \mathrm{C}$ for $2 \mathrm{~h}$ and maintained for $3 \mathrm{~h}$ at constant temperature, then slowly increased to $510^{\circ} \mathrm{C}$ for $2 \mathrm{~h}$, and maintained for $20 \mathrm{~h}$. Hot water was used for quenching $\left(60^{\circ} \mathrm{C}\right)$. For manual aging treatment, the solid solution obtained from room temperature at $150^{\circ} \mathrm{C}$, was held for $26 \mathrm{~h}$ and cooled in the furnace. To prepare the chitosan coating, the magnesium alloy was cleaned with acetone, absolute ethanol and deionized water for 10 minutes and then dried. It was treated with $80 \%$ phosphoric acid for 2 minutes. After cleaning with deionized water, it will dry naturally. Then, chitosan $\left(3 \times 10^{-5}\right.$ Da) with $85 \%$ deacetylation degree was dissolved in $1 \%$ acetic acid solution and stirred for 2.5 hours. After standing and filtering, it was coated on the surface of acid treated alloy. After coating three times, it was dried at $60{ }^{\circ} \mathrm{C}$ for 30 minutes. For flow cutting and polishing, the surface oxidation layer of the sample was removed, and the sample was cut into $1 \times 0.5 \times 3 \mathrm{~cm}$ pieces. Water scrubbing paper was used for rough grinding, and diamond polishing paste was used for mechanical polishing until the surface of the sample had no rough marks. Finally, a fine cast used deerskin to produce the desired finished product.

\section{Preparation and treatment of experimental animals}

Twenty-seven healthy adult female rats were randomly divided into a sham-operated group (group A), an uncoated Mg-Ca alloy group (group B), and a chitosan-coated Mg-1Zn-0.3 Zr-2Gd-1Ca alloy group (group $\mathrm{C}$ ). The osteoporosis model was established by removing the rat ovaries after 4 weeks of feeding under the same conditions (constant temperature of $23{ }^{\circ} \mathrm{C} \pm 0.5{ }^{\circ} \mathrm{C}$ and constant humidity of $45-50 \%)$. The rats were used after surgery and after they had completely recovered from surgery. Anesthesia was performed via the ear vein (sodium pentobarbital, $30 \mathrm{mg} / \mathrm{kg}$ ). Routine skin preparation included disinfection. Aseptic sheets were taken from the middle part of the right femur, and the layers of tissues were cut to expose the femur; a $10 \mathrm{~mm} \times 2 \mathrm{~mm}$ bone defect was fabricated artificially and the fracture section was simulated. The corresponding alloy specimens were placed between the bone defects and fixed well. The sham operation group had fracture sections without alloy materials (Figure 1). After surgery, hydrogen peroxide and sterile saline were applied to sterilize the region, and suturing was performed, one by one. The animals moved freely after surgery and were maintained in cages. Continuous intramuscular injection of gentamicin $(400,000$ units/day for 1 week) was given after surgery to prevent infection. $\mathrm{X}$-ray images were taken of the surgical areas at 7 , 14 , and 21 days after surgery. The rats were randomly euthanized in groups of three, and the alloy implants, liver and kidney tissues were extracted for further study.

\section{Study on biodegradability in vivo}

In this study, firstly, the general observations of experimental rats were observed, such as postoperative mental state, activity, diet, and wound healing state, etc. The changes of surgical areas in every group at different times after surgery were observed by X-ray irradiation. The extracted alloy implants were analyzed by scanning electron microscopy (SEM), and were further analyzed by parallel EDS spectra.

\section{In vivo compatibility study}

The pathological changes of liver and kidney in every group were analyzed by HE staining at different times after operation. The effects of alloy degradation on the rats were analyzed by measuring the concentrations of $\mathrm{Mg}$ and $\mathrm{Ca}$ ions in peripheral blood samples. In this study, hematoxylin \& eosin (HE) staining solution was bought from Shanghai Bogu Biotechnology, Shanghai, China. 


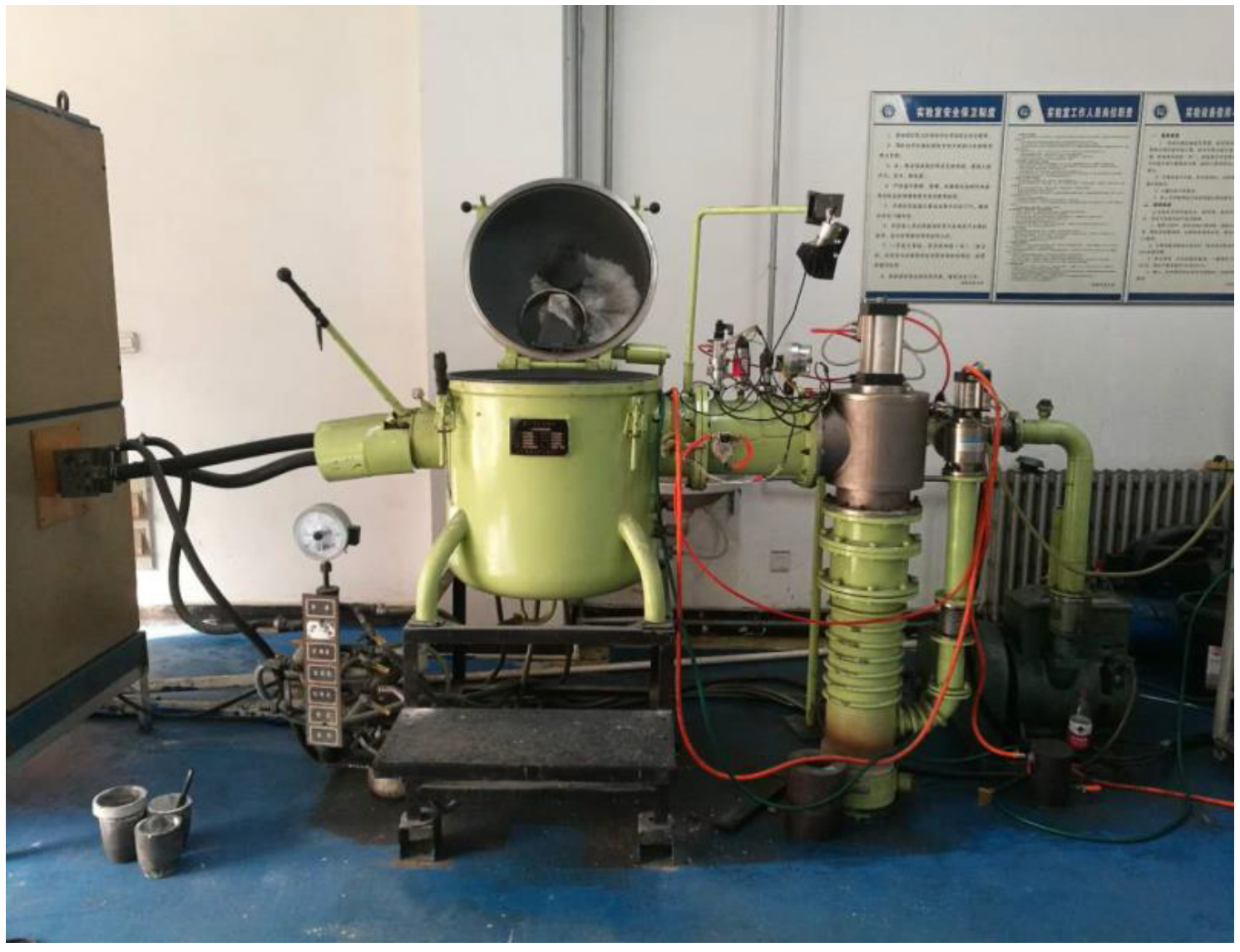

Figure 1a: The image and spec of vacuum smelting resistance furnace surgery used in this study.

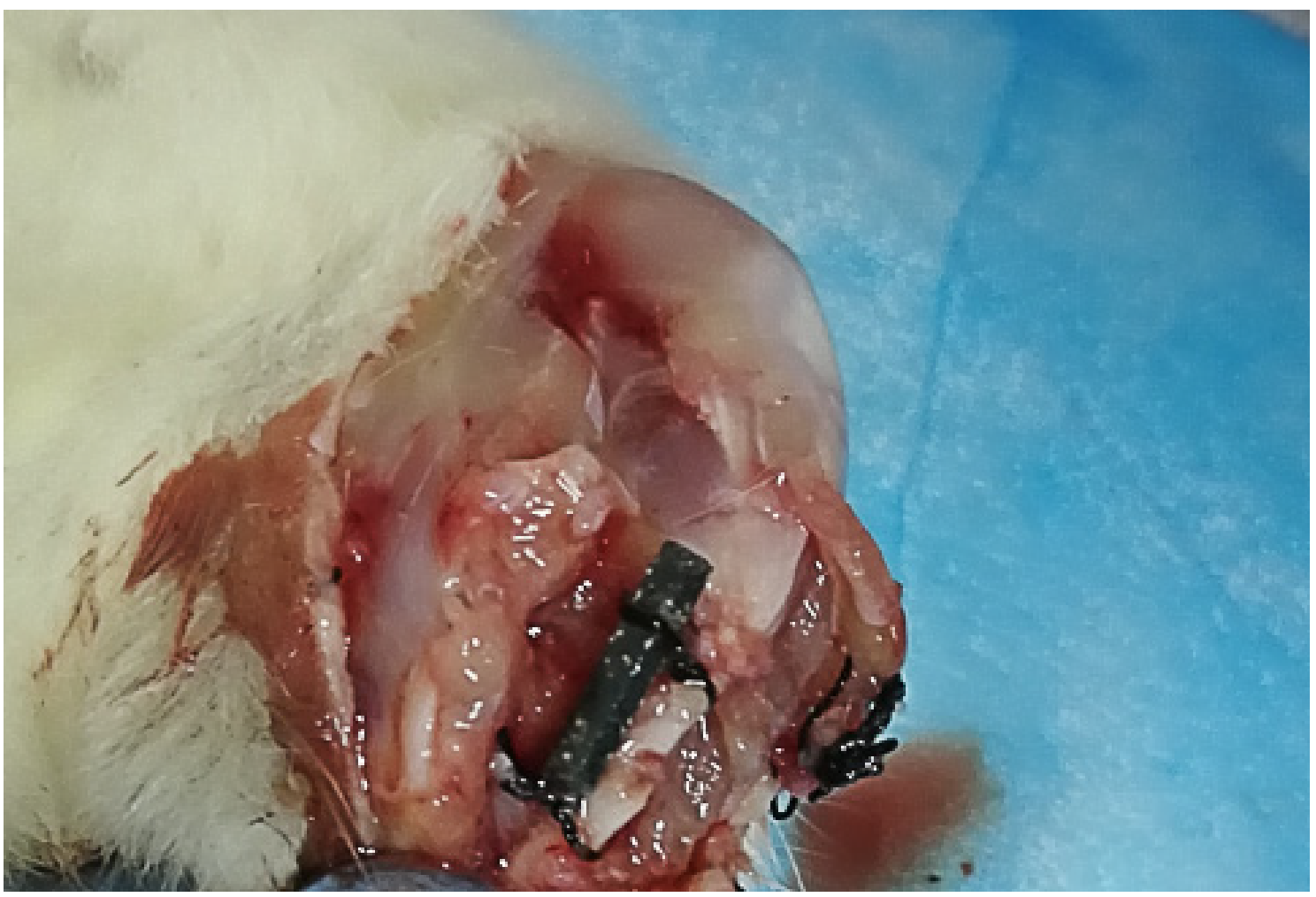

Figure 1b: Fixation of the Mg-1Zn-0.3 Zr-2Gd-1Ca alloy bone nail during a surgery. 


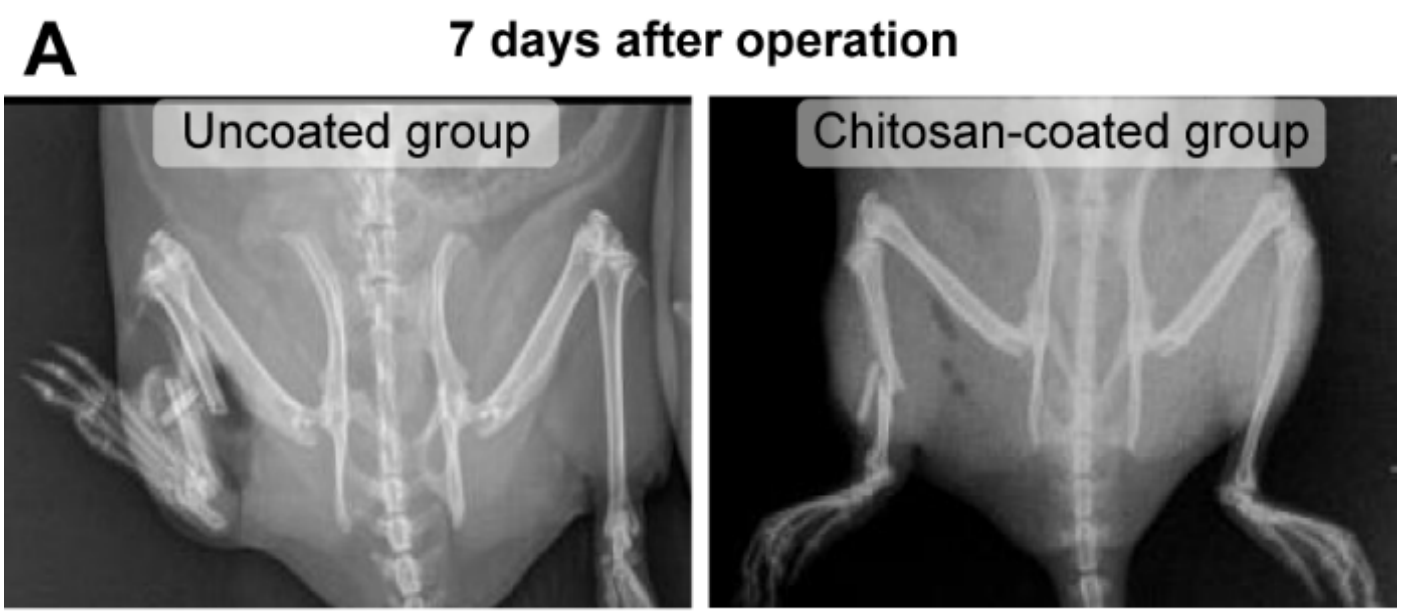

B 14 days after operation
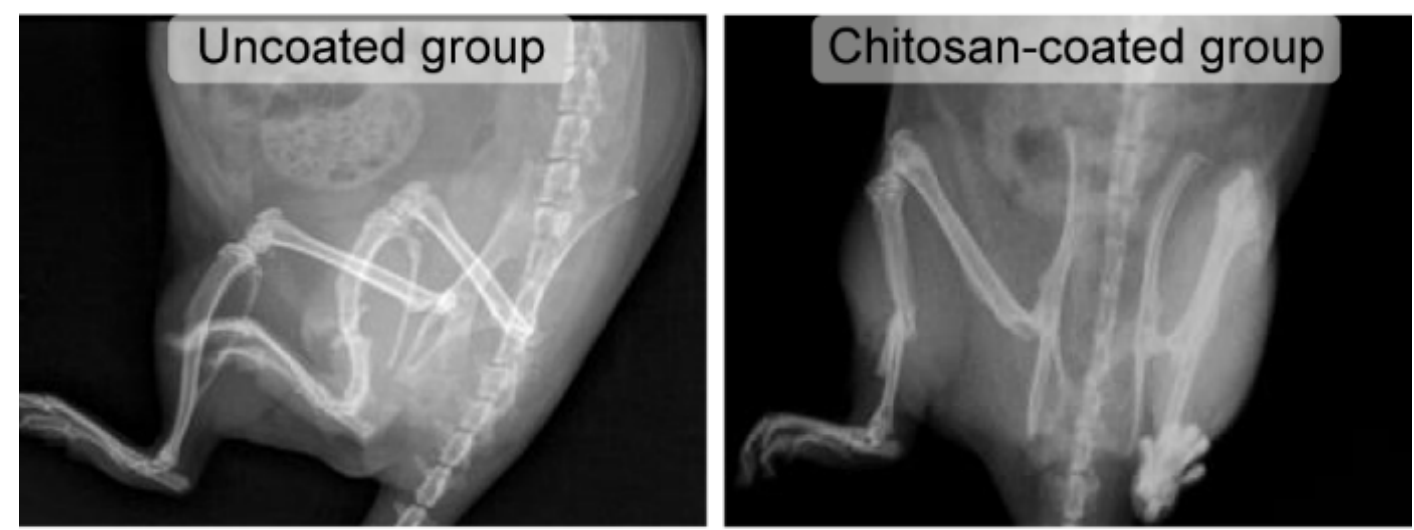

C

21 days after operation
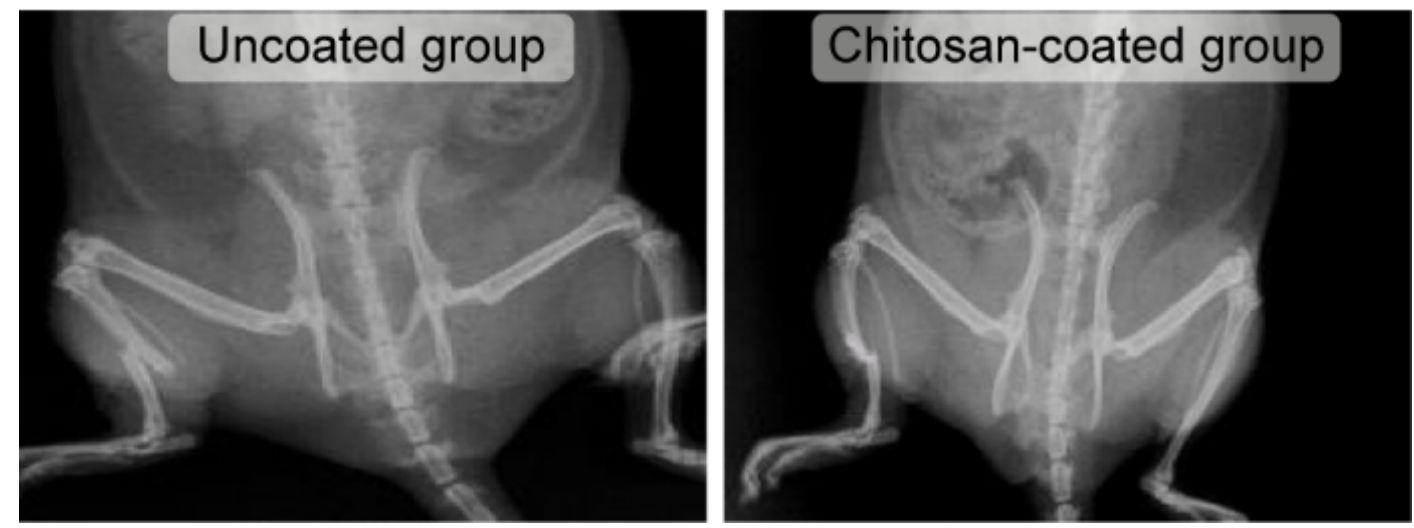

Figure 2: $\mathrm{X}$-ray changes of rats in uncoated and chitosan coated rats groups at different postoperative times: (A) X-ray films at 7 days after operation; (B) X-ray films at 14 days after operation; (C) X-ray films at 21 days after operation.

\section{Statistical Analysis}

The experimental data are expressed as the mean \pm SD. One-way analysis of variance and LSD- $t$ tests were used and assessed by SPSS, version 19.0 software (SPSS, Chicago, IL, USA) A value of $P<0.05$ was considered to be statistically significant.

\section{Results and Discussion}

\section{Postoperative general conditions}

The postoperative vital signs were stable in all operated groups, and the behavior and food intake were not significantly affected. Group B and $C$ rats showed normal postoperative right limb 
movements after surgery, but this was significantly affected in group $A$ rats. No incision infection, subcutaneous emphysema, or death occurred during the observation period.

\section{Evaluation of degradation study in vivo}

X-ray observations: Postoperative $\mathrm{X}$-ray images shows that both group $B$ and group $C$ rat composite gold implants were well-fixed, without displacement or shedding, and the density of the implants was similar to that of the rat femurs. The group $B$ and $C$ rat composite gold implants were clearly outlined, and group B showed a slight gas shadow in the surgical area at postoperative 7 days, with different degrees of inflammatory exudation observed around the fracture sites of both groups, as shown in Figure 2A. At postoperative 14 days, the contour of the implants in group $C$ rats was still clear; however, in group $B$ rats the contour of the implants was slightly defective, and the surrounding gas shadow was reduced. In addition, the inflammatory exudation in the fracture area was less than before, as shown in Figure 2B. At postoperative 21 days, the implant development in group $B$ was not clear, while only a few defects were noted in group $\mathrm{C}$. The inflammatory exudation in the fracture area gradually disappeared in both groups, as shown in Figure 2C.

In the study on biodegradability of $\mathrm{Mg}$ alloy bone nail, the X-ray images indicated that the two types of alloys had undergone different degrees of degradation in vivo, and the degradation of uncoated $\mathrm{Mg}-1 \mathrm{Zn}-0.3 \mathrm{Zr}-2 \mathrm{Gd}-1 \mathrm{Ca}$ alloys was faster than that of the chitosan-coated Mg alloys. In addition, the low density gas shadows in group $B$ may have been be caused by $\mathrm{H}_{2}$ produced because of the fast degradation of the alloy. However, they were absorbed quickly without subcutaneous emphysema, consistent with the study of Mueller, et al. [36]. In addition, the inflammatory exudation in the two groups was related to implants and surgical trauma. However, the inflammatory exudation in both groups was absorbed quickly and had no significant effect on the postoperative recovery of rats.

SEM observation and EDS analysis: SEM results shows that the surface cracks of group Brats samples were different at 7 days after operation. The erosive sediment particles were large, and flaky corrosion products appeared locally, which were loose and obvious, and fell off from the substrate, while the surface of Group C was intact, only a small amount of cracks appeared, and the corrosion products were uniformly deposited as shown in Figure 3A. At postoperative 14 days, the surface cracks of group B rat samples increased further, filling the entire field of view, and a large number of triangular or irregular polygon cracks appeared, with a width of approximately $3 \mu \mathrm{m}$. The surface of the alloy was uneven, the structure was loose, and the corrosion pit was partially visible. The surface structure of the sample of group $C$ rats was dense, and the sedimentary layer with uneven corrosion products and a small number of corrosion pits were visible. The cracks were significantly less than that of group $B$ rats as shown in Figure 3B. The cracks in group $B$ samples were further deepened and widened at postoperative 21 days, and white corrosion products were observed on the crack edges, group $C$ specimens had a few cracks, shallow cracks, and a narrow width, but a large amount of flocculent corrosion products could be seen on the surface as shown in Figure $3 \mathrm{C}$. The main degradation products of group $B$ and $C$ rats were $M g$, oxygen ( $O$ ), $\mathrm{Ca}$, and $\mathrm{Zn}$, as assessed by EDS analyses. There was no significant difference in the composition of the products. At the same time, a small amount of $Z r$, phosphate $(\mathrm{P})$, and $\mathrm{Gd}$ elements were also detected, and with the prolongation of the postoperative time, the mass fractions of $\mathrm{Mg}$ and $\mathrm{O}$ in $\mathrm{B}$ and $\mathrm{C}$ composite metal gradually decreased, while the mass fractions of $\mathrm{Ca}$ and $\mathrm{Zn}$ gradually increased as shown in Figure 4. In addition, the decreased $\mathrm{Mg}$ and $\mathrm{O}$ content in group $\mathrm{C}$ was significantly lower than that in group $B$, while the increase of $\mathrm{Ca}$ and $\mathrm{Zn}$ content was significantly higher than that of group $B$, with significant differences between the two groups $(P<0.05)$ as shown in Figure 5.

SEM images shows that there were only a few cracks in Mg alloy coated with chitosan at postoperative 7 days. At postoperative 14 days, the corrosion products compactly accumulated on the surface of the alloy and did not fall off. At postoperative 21 days, the overall structure of the alloy remained intact, and the corrosion products further accumulated on the surface, forming a protective layer structure to some extent. This result was consistent with the X-ray images, which showed a faster corrosion rate of the uncoated $\mathrm{Mg}$ alloy. Combined with the results of previous studies [37,38], we hypothesize that the chitosan coating played a protective role, delaying the degradation rate of the Mg alloy. 

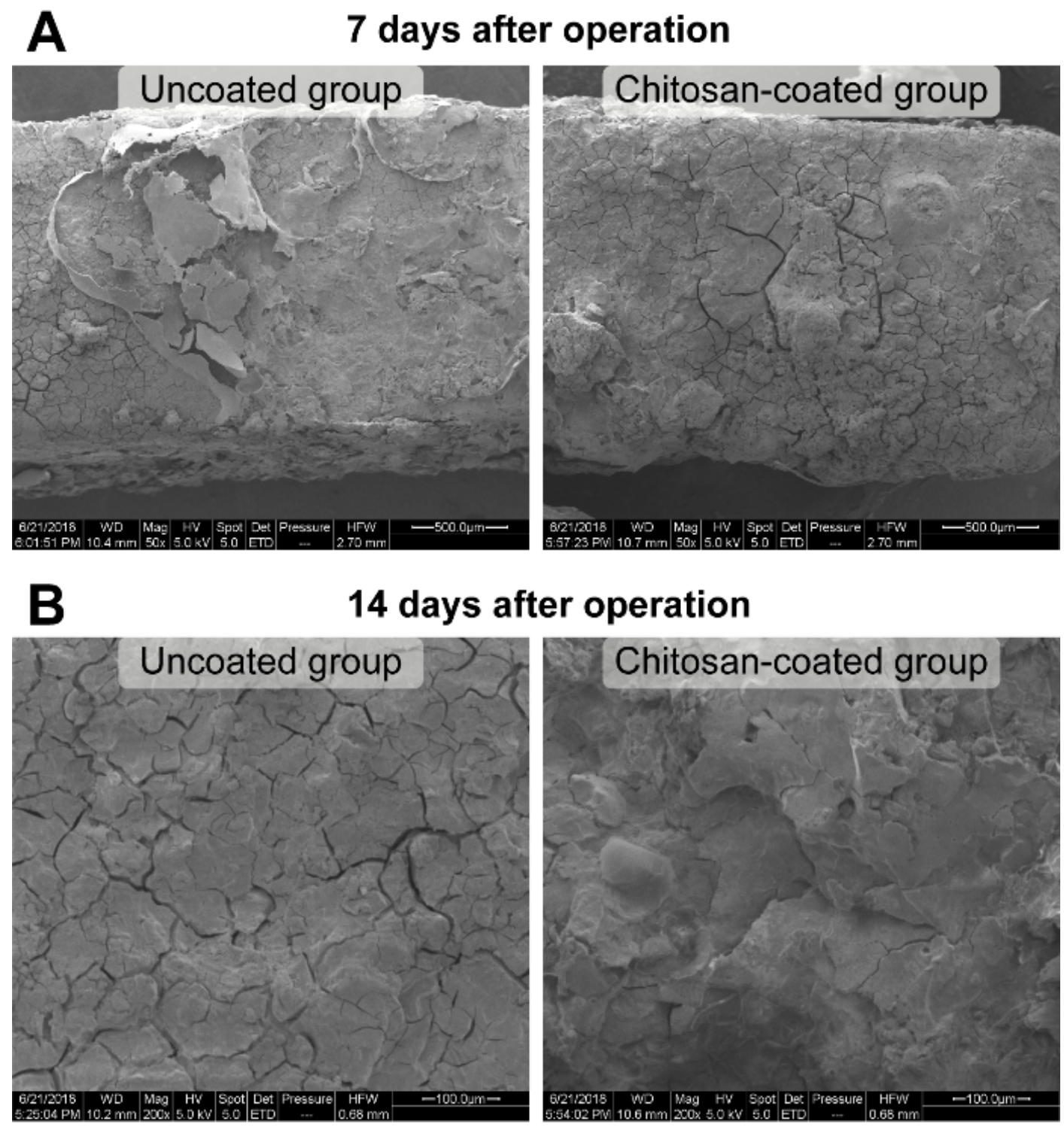

C

21 days after operation
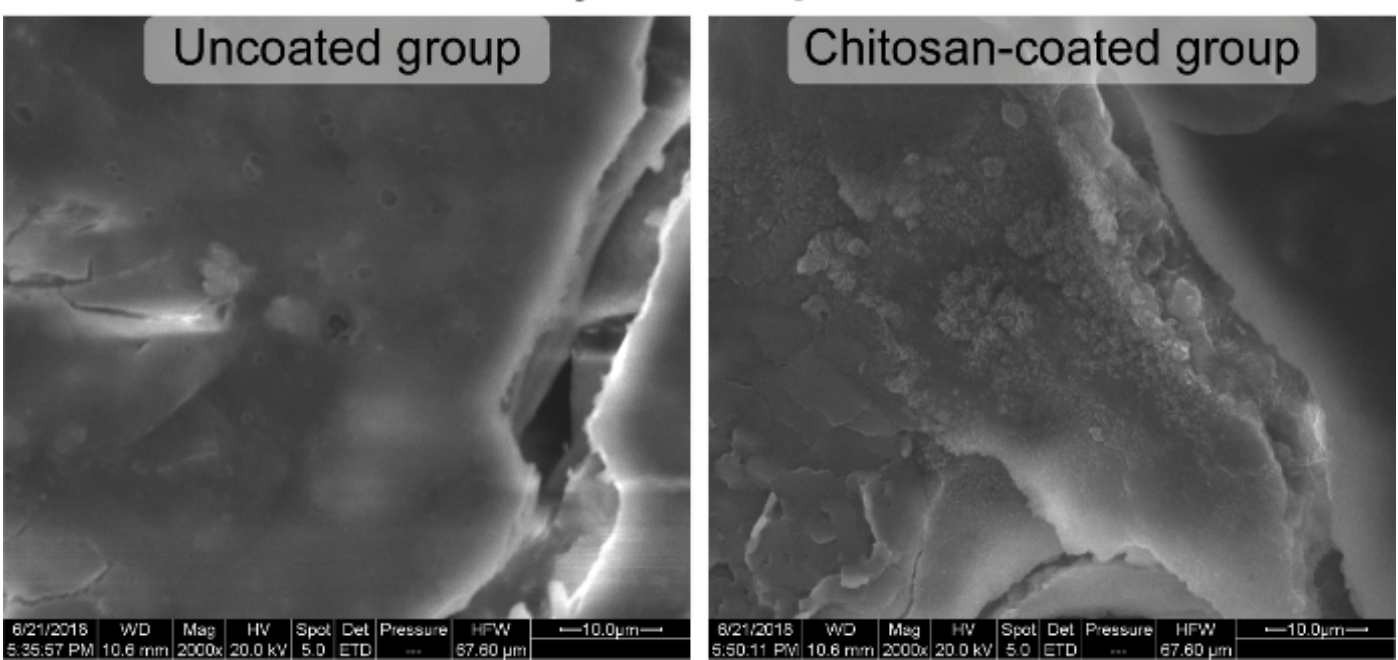

Figure 3: SEM of rat sections in uncoated and chitosan coated groups at different times after surgery: (A) The samples at postoperative 7 days; (B) The samples at postoperative 14 days; (C) The samples at postoperative 21 days. 

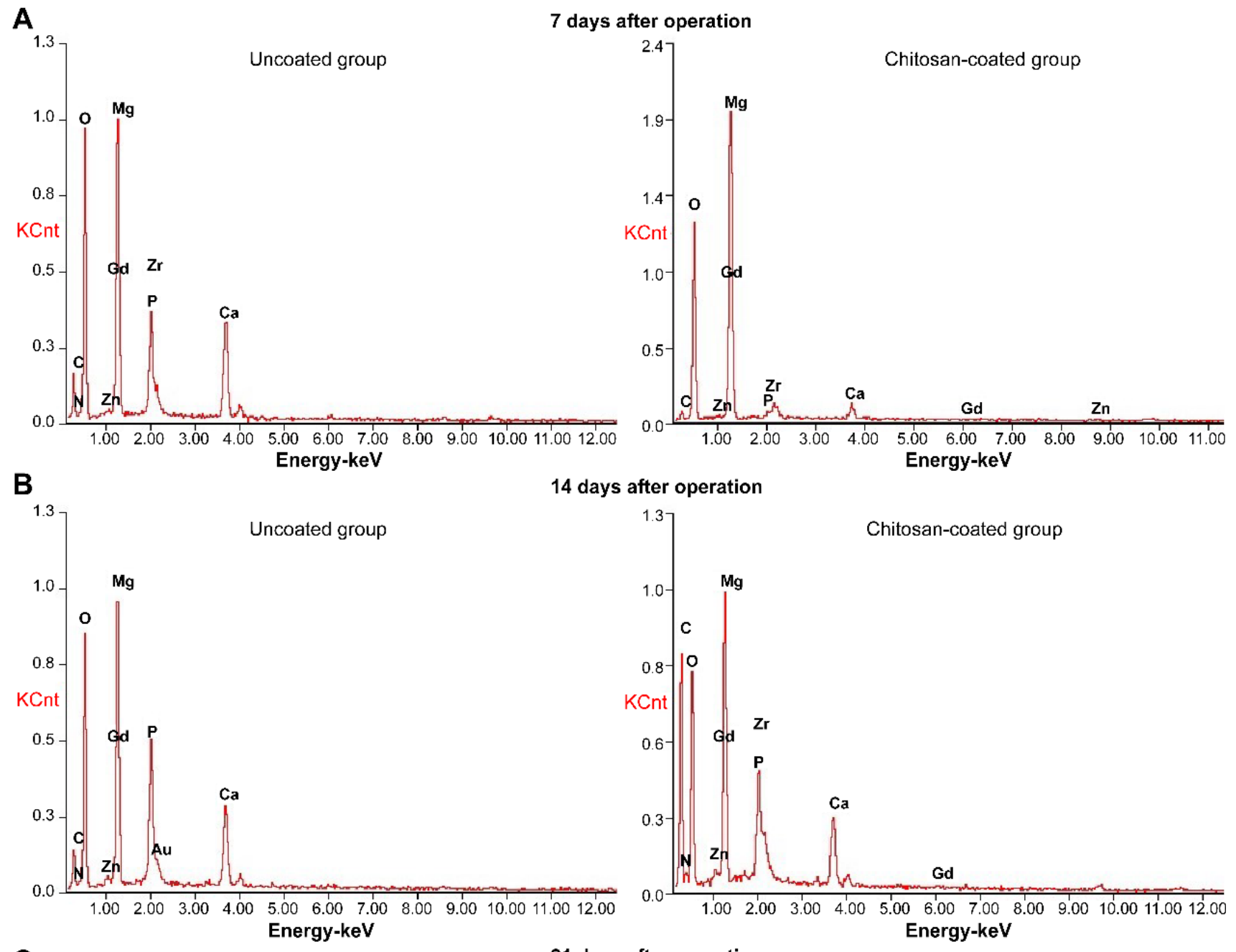

C

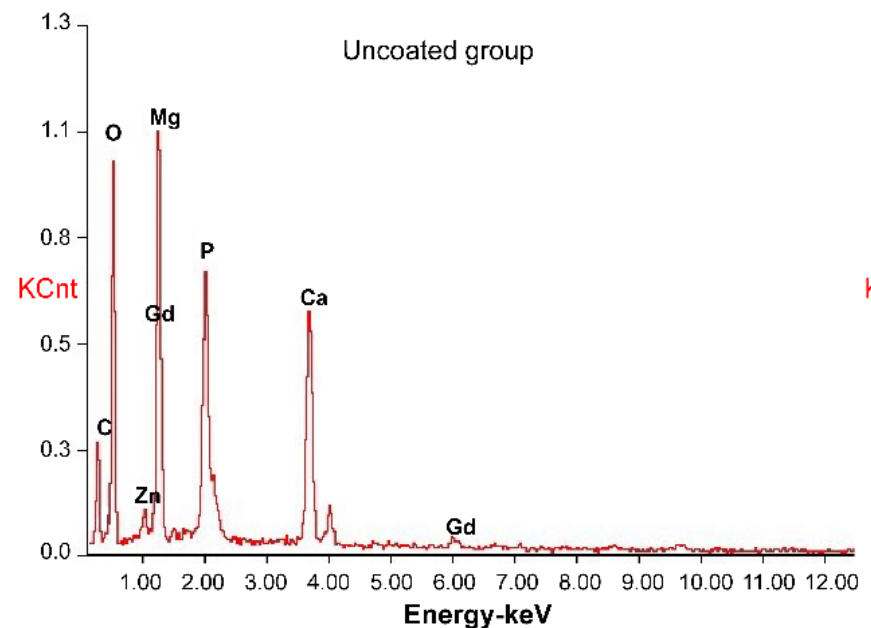

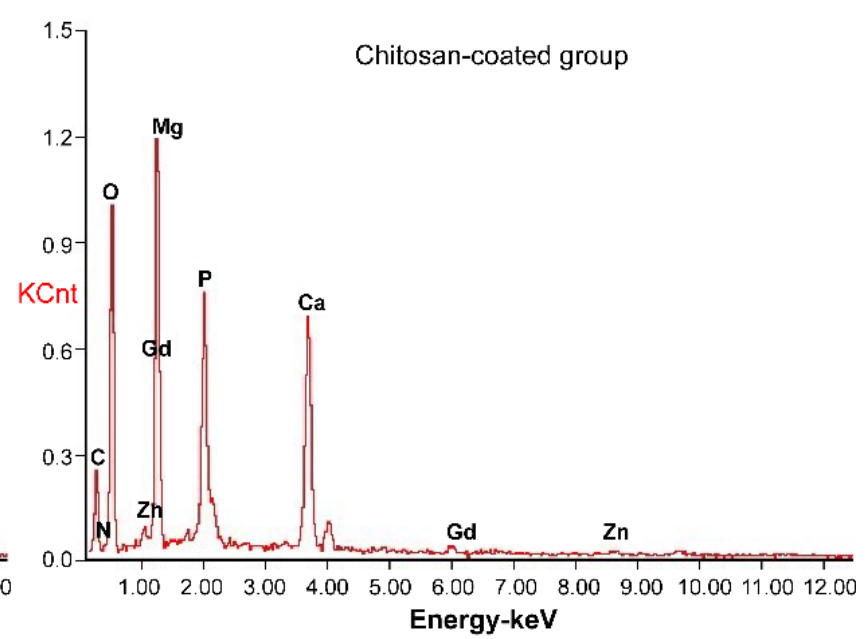

Figure 4: EDS changes of rats in uncoated and chitosan coated rats groups at different postoperative times: (A) EDS at 7 days after operation; (B) EDS at 14 days after operation; (C) EDS at 21 days after operation.

Mg alloy, as a kind of degradable material, whose rapid degradation rate and excessive gas production limit its clinical applicability $[39,40]$. Pure $\mathrm{Mg}$ alloys were firstly applied as fracture internal fixation by Lambotte [41] in 1907, but the procedure failed because of its rapid degradation. Seitz, et al.
[42] also found that ordinary Mg-Ca alloys without coating had fast degradation rates in the body and it was difficult to achieve good results in internal fixation of fractures. Subsequently, others have found that coating on the surface was an effective method to delay the degradation rate of the alloy, 

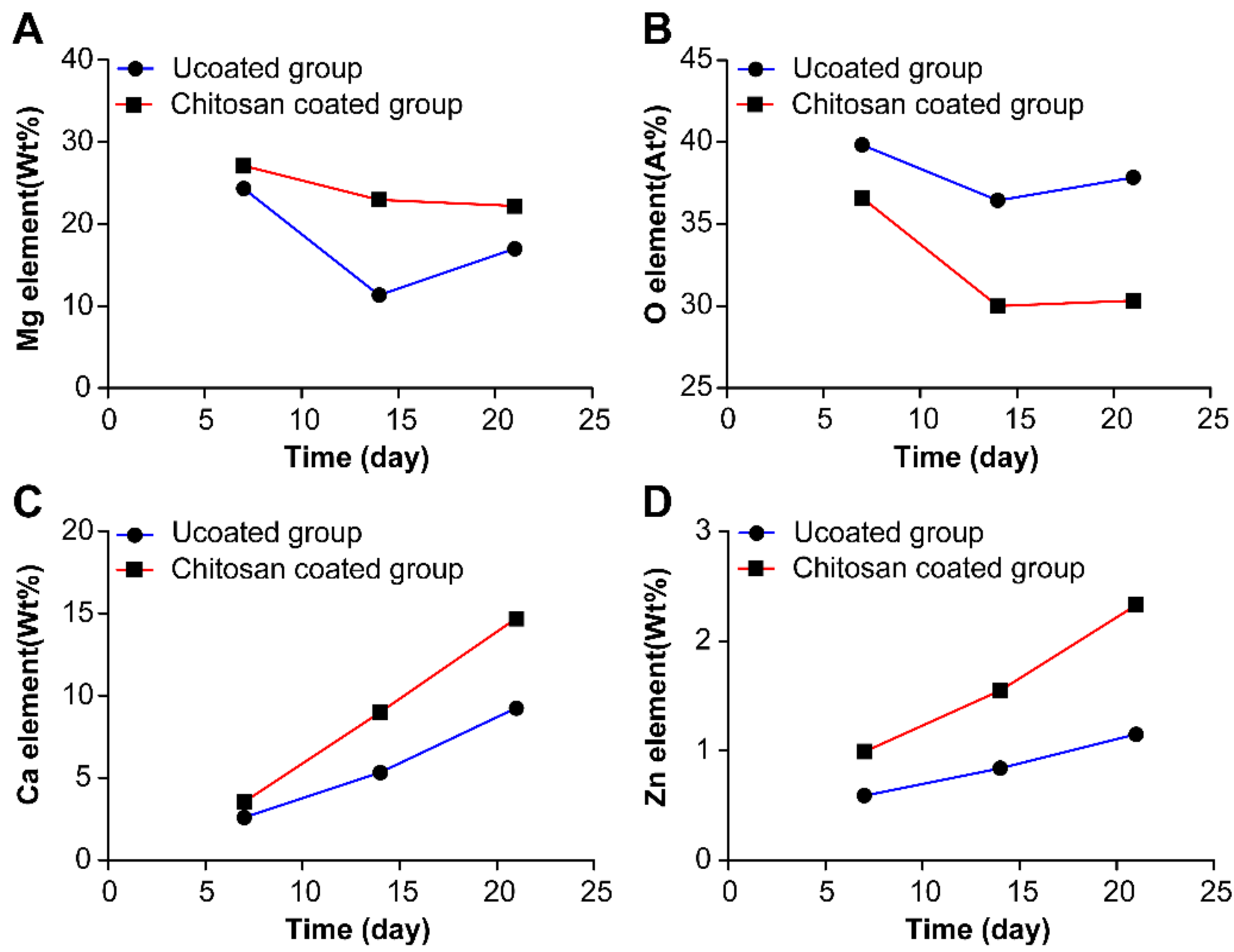

Figure 5: Variation curves of main elements' mass fraction after degradation of the Mg alloy at different postoperative times: (A) The mass fraction of Mg element; (B) The mass fraction of O element; (C) The mass fraction of Ca element; (D) The mass fraction of Zn element.

such as chitosan coating $[20,43,44]$, and chitosan is an alkaline aminopolysaccharide with a stable structure. Based on the above considerations, a Mg-1Zn-0.3Zr-2Gd-1Ca alloy with a chitosan coating was fabricated and used a rat osteoporosis model produced by ovariectomy.

Although the degradation rate of the $\mathrm{Mg}-1 \mathrm{Zn}$ $0.3 \mathrm{Zr}-2 \mathrm{Gd}-1 \mathrm{Ca}$ alloy containing chitosan coating was lower than that of the uncoated Mg alloy in this work, its degradation rate was still faster than that of the fracture healing process, so the performance still needs further improvement. The EDS spectrum analysis showed that the main degradation products of $B$ and $C$ gold were $\mathrm{Mg}, \mathrm{O}, \mathrm{Ca}$, and $\mathrm{Zn}$. A small amount of $\mathrm{Zr}, \mathrm{P}$, and $\mathrm{Gd}$ were also detected, and there was no significant difference in the product composition. Further statistical analyses showed that with the prolongation of the postoperative time, the mass fraction of $\mathrm{Mg}$ and $\mathrm{O}$ in the $\mathrm{B}$ and
C combination gold decreased gradually, and the rate of decline in group $C$ was significantly lower than that in group $B$, while the mass fraction of $\mathrm{Ca}$ and $\mathrm{Zn}$ gradually increased. The rate of increase in group $C$ was significantly higher than that in group $B$, and this difference between groups was significant. Combined with the previous results $[45,46]$, we analyzed the results of X-ray and scanning electron microscopy images and validated this difference. It was further confirmed that the decomposition rate of uncoated $\mathrm{Mg}$ alloys was faster than that of coated $\mathrm{Mg}$ alloys, and that the degradation rate of uncoated $\mathrm{Mg}$-Ca alloys could be delayed to some extent by chitosan coating. In conclusion, this study suggests that chitosan coating can significantly improve the corrosion resistance of magnesium alloy nails, although the degradation rate of magnesium alloy after chitosan modification is still relatively fast. 

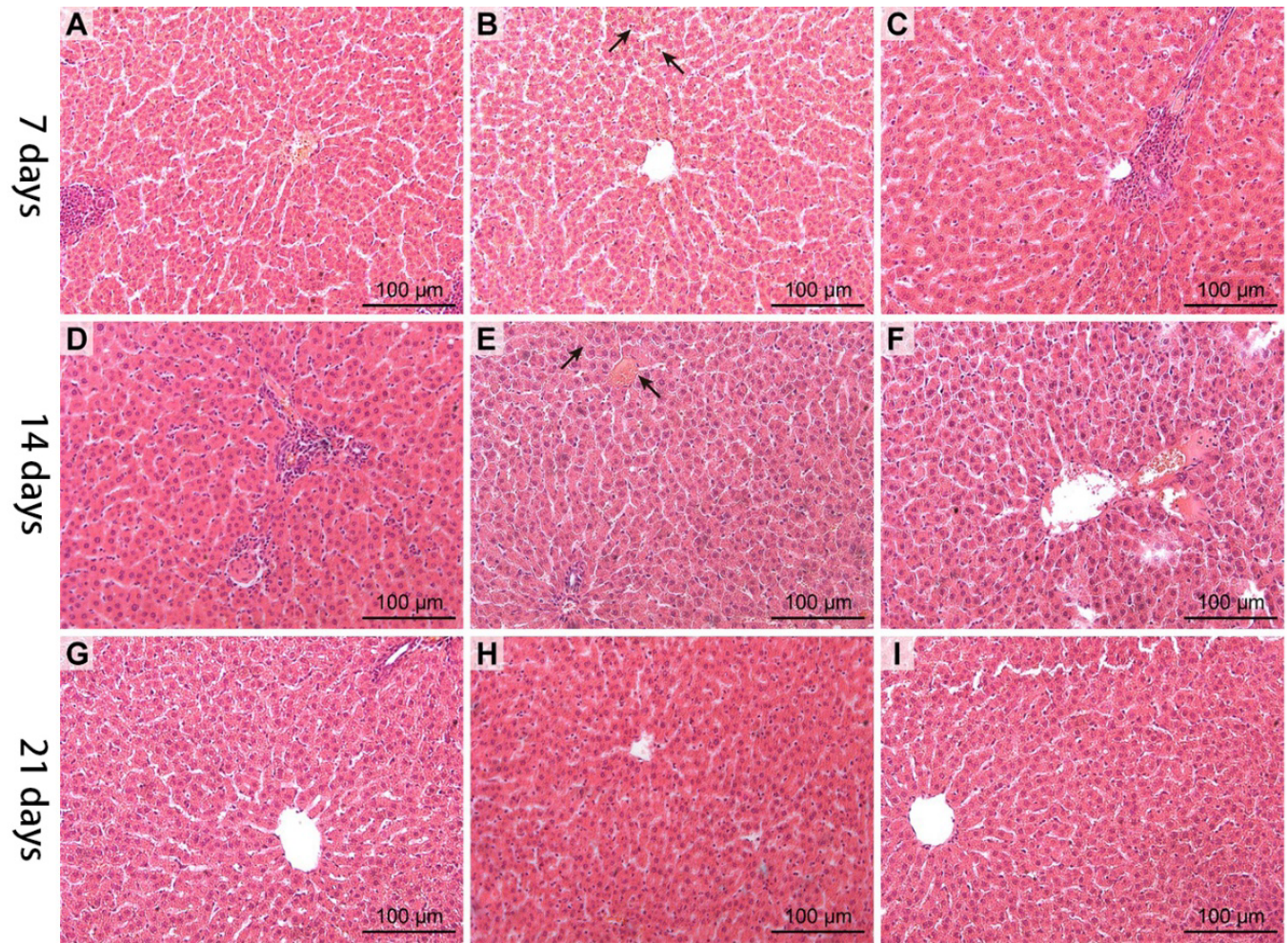

Figure 6: Histological changes of liver sections in every group at different postoperative times: $(A, D, G)$ The sham operation group; $(\mathrm{B}, \mathrm{E}, \mathrm{H})$ The uncoated Mg alloy group; $\mathrm{C}, \mathrm{F}, \mathrm{I})$ The chitosan-coated Mg alloy group, respectively.

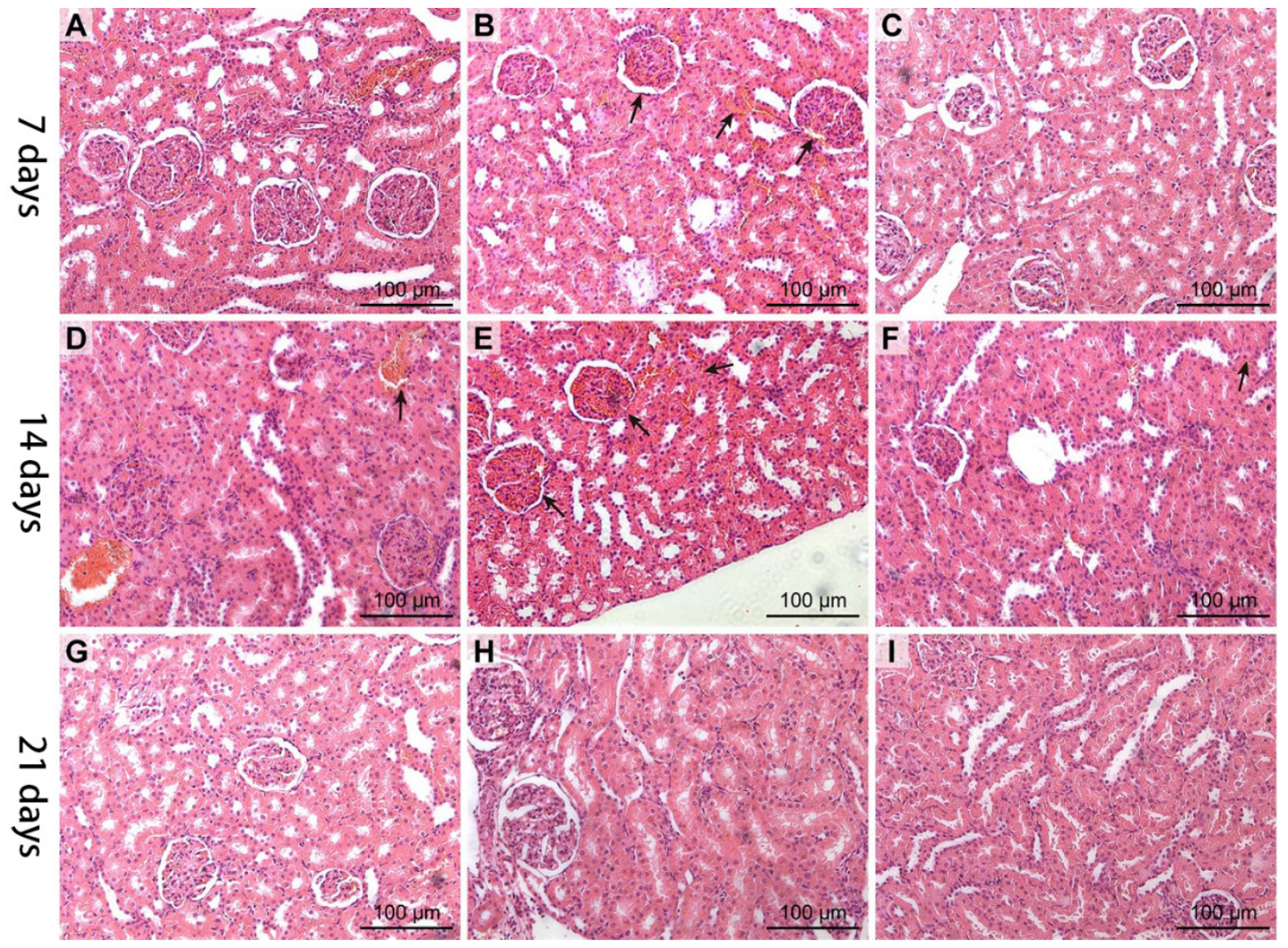

Figure 7: Histological changes of kidneys from rats of different groups at different times: $(A, D, G)$ The sham operation group; $(B, E, H)$ The uncoated $M g$ alloy group; $(C, F, I)$ The chitosan-coated Mg alloy group, respectively. 


\section{Biosafety evaluation in vivo}

Postoperative histopathological evaluation of liver in rats: Figure 6 shows the histopathological changes of liver sections in different treated group at different postoperative times. A, B and C were the histopathological sections of liver in sham operation group, uncoated $\mathrm{Mg}$ alloy group and chitosan-coated $\mathrm{Mg}$ alloy group at postoperative 7 days, respectively. And there was scattered congestion between hepatic lobules in the uncoated Mg alloy group (Figure 6B, black arrows), however, there were no obvious abnormalities found in sham operation group as shown in Figure 6A, Figure $6 \mathrm{~B}$ and Figure $6 \mathrm{C}$. Moreover, the cells were arranged regularly, and no obvious inflammatory cell infiltration was observed as shown in Figure $6 \mathrm{~A}$, Figure $6 \mathrm{C}$, Figure $6 \mathrm{D}$, Figure $6 \mathrm{E}$ and Figure $6 \mathrm{~F}$ were the histopathological sections of liver in sham operation group, uncoated $\mathrm{Mg}$ alloy group and chitosan-coated $\mathrm{Mg}$ alloy group at postoperative 14 days, respectively. And scattered congestion was still seen between hepatic lobules in uncoated $\mathrm{Mg}$ alloy groups (as shown in Figure 6E, black arrows), but the structure of the hepatic lobules and hepatic sinusoids in the other two groups (Figure 6D and Figure 6F) were intact. At postoperative 21 days, hepatic interlobular congestion was gradually absorbed completely in the uncoated $\mathrm{Mg}$ alloy group samples in Figure $6 \mathrm{H}$, and there was no significant damage in the other two groups in Figure $6 \mathrm{G}$ and Figure 61 .

Postoperative histopathological evaluation of renal in rats: In this study, Figure 7 shows the results of renal tissue section microscopic observed in different groups at different times. At postoperative 7 days, there were intact glomerular and tubular structures in the sham-operated group (Figure 7A) and the chitosan-coated Mg alloy group (Figure 7C), and there was no obvious damage, but had significant congestion in the glomeruli (as indicated by black arrows) in the uncoated Mg alloy group (Figure 7B). At postoperative 14 days, a small amount of congestion was observed in the sham-operated group (Figure 7D) and the chitosan-coated Mg alloy group (Figure 7F), however, the glomeruli and tubules were structurally intact and the congestion was significantly less than that of the uncoated layer Mg alloy group (Figure 7E, black arrows). At postoperative 21 days, the blood stasis of the three groups was completely normal, and the cell arrangement was regular as shown in Figure 7G, Figure $7 \mathrm{H}$ and Figure $7 \mathrm{I}$.

Regarding the biological toxicity test results in this study, liver and kidney tissues of the rats were analyzed by $\mathrm{HE}$ staining at different postoperative times. At postoperative 7 days, the liver tissue of the uncoated $\mathrm{Mg}$ alloy group showed scattered blood between the hepatic lobules as shown in Figure 6 . There was also scattered congestion along the glomeruli and renal tubules, while the kidney tissue in the chitosan-coated $\mathrm{Mg}$ alloy group and the sham-operated group showed slight congestion at postoperative 14 days, but were significantly less than the uncoated $\mathrm{Mg}$ alloy group, and was absorbed quickly as shown in Figure 7. This may have a certain relationship with the faster degradation rate of the Mg alloy. However, the results of subsequent peripheral blood tests showed that both the uncoated $\mathrm{Mg}$ alloy group and the chitosan-coated $\mathrm{Mg}$ alloy group had a certain degree of fluctuation in serum $\mathrm{Mg}$ and $\mathrm{Ca}$ after surgery, but they were all within the normal ranges. This did not have a significant impact on the postoperative recovery of the mouse. The results showed that the chitosan-coated Mg-1Zn-0.3Zr-2Gd-1Ca alloy possessed less effects on rat liver and kidney tissues and Mg-1Zn-0.3Zr-2Gd-1Ca alloy had good biocompatibility, which was consistent with the results of many research reports $[47,48]$.

Serum $\mathrm{Mg}$ and $\mathrm{Ca}$ ion concentrations analysis in the postoperative rats: The serum $\mathrm{Mg}$ ion concentrations of the rats in groups $A, B$, and $C$ were 1.20 $\pm 0.21 \mathrm{mmol} / \mathrm{dL}, 1.19 \pm 0.55 \mathrm{mmol} / \mathrm{dL}$ and $1.21 \pm$ $0.08 \mathrm{mmol} / \mathrm{dL}$, respectively at postoperative 1 day, and the serum $\mathrm{Ca}$ ion concentrations were $2.35 \pm$ $0.82 \mathrm{mmol} / \mathrm{dL}, 2.40 \pm 0.73 \mathrm{mmol} / \mathrm{dL}, 2.38 \pm 0.79$ $\mathrm{mmol} / \mathrm{dL}$, respectively. The concentration of $\mathrm{Mg}$ and $\mathrm{Ca}$ in group $\mathrm{B}$ and $\mathrm{C}$ increased slightly within postoperative 14 days, and then decreased gradually, but did not exceed the normal range. There was no significant difference in $\mathrm{Mg}$ ions between the preoperative and postoperative time points ( $P$ $>0.05)$. The differences between groups $A, B$, and $C$ were not significant $(P>0.05)$. The changes of $C a$ ion concentrations were similar with that of $\mathrm{Mg}$ ion concentrations as shown in Figure 8.

Figure 8 Changes of $\mathrm{Mg}$ and $\mathrm{Ca}$ ion concentrations in the peripheral blood of rats in different groups at different postoperative times. Within 14 days after surgery, the serum $\mathrm{Mg}$ and Ca concen- 

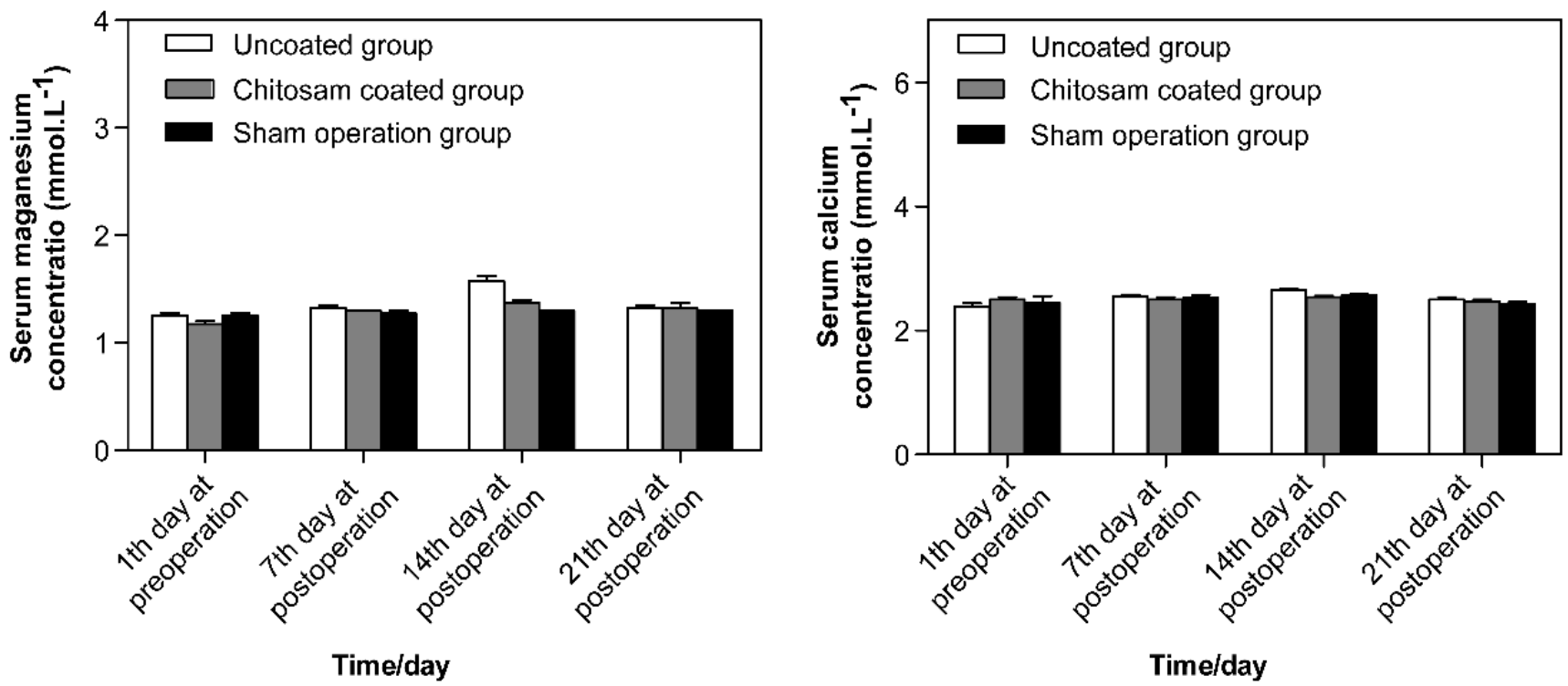

Figure 8: Changes of $\mathrm{Mg}$ and $\mathrm{Ca}$ ion concentrations in the peripheral blood of rats in different groups at different postoperative times.

trations of rats in uncoated $\mathrm{Mg}$ alloy group and chitosan-coated $\mathrm{Mg}$ alloy group increased gradually, and then decreased, but did not exceed the normal range.

In the study all three groups of rats recovered after surgery, and there were no incision infections, rejections, and other related complications, similar to the reports by Griebel [49] and Henderson, et al. [50]. This showed that the Mg-1Zn-0.3Zr-2Gd-1Ca alloy implant had good compatibility with rat tissues. Alkaline phosphatase is often considered to be one of the markers of bone formation activity, and $\mathrm{Zn}$ ion is one of the components of the alkaline phosphatase active center, which can increase the enzyme activity of alkaline phosphatase, and in turn, contribute to bone formation [51,52]. In addition, $\mathrm{Ca}$ ions can promote the formation of new bone, which has been confirmed by numerous studies [53-55]. Moreover, one of the important causes of osteoporosis is the lack of $\mathrm{Ca}$ in the body leading to a decrease in bone density, which in turn causes fractures from the action of external forces. Therefore, Ca has a unique advantage for use in $\mathrm{Mg}$ alloys as an internal fixation material for the treatment of osteoporotic fractures. However, simple $\mathrm{Mg}$ alloys currently still have limitations, such as poor biocompatibility, toxicity, and rejection.

\section{Conclusion}

The Mg-1Zn-0.3Zr-2Gd-1Ca alloy designed had good biocompatibility and safety. It delayed the degradation rate to some extent after adding chitosan coating and showed some future improvements for possible clinical applications. Although chitosan coating can significantly improve the corrosion resistance of magnesium alloy bone nails, however, regarding the fracture healing process that the degradation rate is still faster, which can not meet temporarily the clinical application, so further study on the controllability of degradation rate of magnesium alloy is needed. In addition, the histopathology of liver and kidney showed that there was no significant abnormality after the chitosan coated magnesium alloy bone nail was implanted into rats. Moreover, the serum concentrations of magnesium and calcium were not also significantly abnormal. It is suggested that the magnesium alloy bone nail modified by chitosan coating has good biological compatibility. In view of that, this study provides a reference for the establishment of a new treatment method for osteoporosis fracture.

\section{Author Contributions}

Authors who have made significant contributions to this study are as follows: Conceptualization: Zhanhui Wang and Yawei Li; Methodology: Zhanhui Wang, Zongbin Sun, Tinghe Duan; Software: Zongbin Sun, Shaopeng Liu; Validation: Zhanhui Wang and Yawei Li, Zongbin Sun, Jiuba Wen and Tinghe Duan; Formal analysis: Zongbin Sun, Bingbing Zhang; Investigation: Yawei Li, Zongbin Sun; Resources: Zhanhui Wang; Data curation: Bingbing Zhang, Zhanhui Wang; Writing-original draft 
preparation: Yawei Li, Zongbin Sun; Writing-review and editing: Zhanhui Wang; Visualization: Zhanhui Wang; Supervision: Zhanhui Wang; Project administration: Zhanhui Wang; Funding acquisition: Zhanhui Wang. All authors have read and agreed to the published version of the manuscript.

\section{Funding}

This work was funded by the National Natural Science Foundation of China (No. U04825), the Key Scientific and Technological Projects of Henan Province China (No. 2102310012), the Natural Science Foundation of Henan Province (No. 2300410241), and the Science and Technology Development Projects of Luoyang City (No. 03006A-3), the National key Research and Development Program of China (2018YFC1106703).

\section{Acknowledgements}

We are very grateful to the support by the $\mathrm{Na}$ tional Natural Science Foundation of China, the Key Scientific and Technological Projects of Henan Province China, the Natural Science Foundation of Henan Province, and the Science and Technology Development Projects of Luoyang City. The authors would like to thank the Duoease Scientific Service Center for excellent language editing service and suggestions for figure revision.

\section{Conflicts of Interest}

There are no competing interests to declare in this paper.

\section{References}

1. Hingsammer L, Grillenberger $M$, Schagerl $M$, Michael $\mathrm{M}$, Stefan $\mathrm{H}$, et al. (2018) Biomechanical testing of zirconium dioxide osteosynthesis system for Le Fort I advancement osteotomy fixation. Journal of the Mechanical Behavior of Biomedical Materials 77: 34-39.

2. Schorler $H$, Wendlandt $R$, Jürgens $C$, Schulz $A P$, Christian K, et al. (2018) Bone plate-screw constructs for osteosynthesis-recommendations for standardized mechanical torsion and bending tests. Biomed Tech 63: 719-727.

3. Kraemer M, Mueller CW, Hermann M, Sebastian $D$, André S, et al. (2017) Design considerations for a novel shape-memory-plate osteosynthesis allowing for non-invasive alteration of bending stiffness. Journal of the Mechanical Behavior of Biomedical Materials 75: 558-566.

4. Makkar P, Sarkar SK, Padalhin AR, Moon BG, Young
SL, et al. (2018) In vitro and in vivo assessment of biomedical $\mathrm{Mg}$-Ca alloys for bone implant applications. J Appl Biomater Funct Mater 16: 126-136.

5. Kusnierczyk K, Basista M (2017) Recent advances in research on magnesium alloys and magnesium-calcium phosphate composites as biodegradable implant materials. J Biomater Appl 31: 878-900.

6. Meischel M, Hörmann D, Draxler J, Elmar KT, Johannes E, et al. (2017) Bone-implant degradation and mechanical response of bone surrounding Mg-alloy implants. Journal of the Mechanical Behavior of Biomedical Materials 71: 307-313.

7. Liu $H$, Niinomi $M$, Nakai M (2015) $\beta$-Type titanium alloys for spinal fixation surgery with high Young's modulus variability and good mechanical properties. Acta Biomaterialia 24: 361-369.

8. Hidetatsu T, Yu M, Atsushi N, Atsushi K, Masayuki K, et al. (2016) Apatite formation and biocompatibility of a low young's modulus Ti-Nb-Sn alloy treated with anodic oxidation and hot water. PLoS One 11: e0150081.

9. Song Y, Zhang S, Li J, Changli Z, Xiaonong Z, et al. (2010) Electrodeposition of Ca-P coatings on biodegradable $\mathrm{Mg}$ alloy: In vitro biomineralization behavior. Acta Biomaterialia 6: 1736-1742.

10.Aghion E, Levy G, Ovadia S (2012) In vivo behavior of biodegradable Mg-Nd-Y-Zr-Ca alloy. J Mater Sci Mater Med 23: 805-812.

11.Virtanen S (2011) Biodegradable Mg and Mg alloys: Corrosion and biocompatibility. Materials Science and Engineering: B 176: 1600-1608.

12.Li Y, Wen C, Mushahary D, Ragamouni S, Nemani $H$, et al. (2012) Mg-Zr-Sr alloys as biodegradable implant materials. Acta Biomaterialia 8: 3177-3188.

13.Choudhary L, Raman RK (2012) Magnesium alloys as body implants: Fracture mechanism under dynamic and static loadings in a physiological environment. Acta Biomaterialia 8: 916-923.

14.Törne K, Örnberg A, Weissenrieder J (2017) Influence of strain on the corrosion of magnesium alloys and zinc in physiological environments. Acta Biomaterialia 48: 541-550.

15.Luffy SA, Chou DT, Waterman J, Peter DW, Prashant NK, et al. (2014) Evaluation of magnesium-yttrium alloy as an extraluminal tracheal stent. J Biomed Mater Res A 102: 611-620.

16.Kaabi Falahieh AsI S, Nemeth S, Tan MJ (2016) Novel biodegradable calcium phosphate/polymer composite coating with adjustable mechanical properties 
formed by hydrothermal process for corrosion protection of magnesium substrate. J Biomed Mater Res B Appl Biomater 104: 1643-1657.

17. Katarivas Levy G, Leon A, Kafri A, Yvonne V, Jaroslaw WD, et al. (2017) Evaluation of biodegradable $Z n$ $1 \% \mathrm{Mg}$ and $\mathrm{Zn}-1 \% \mathrm{Mg}-0.5 \% \mathrm{Ca}$ alloys for biomedical applications. J Mater Sci Mater Med 28: 174.

18.Jafari S, Harandi SE, Singh Raman RK (2015) A review of stress-corrosion cracking and corrosion fatigue of magnesium alloys for biodegradable implant applications. JOM 67: 1143-1153.

19. Choudhary L, Singh Raman RK, Hofstetter J, Peter JU (2014) In-vitro characterization of stress corrosion cracking of aluminium-free magnesium alloys for temporary bio-implant applications. Materials Science \& Engineering: C 42: 629-636.

20. Hakimi O, Aghion E, Goldman J (2015) Improved stress corrosion cracking resistance of a novel biodegradable EW62 magnesium alloy by rapid solidification, in simulated electrolytes. Materials Science \& Engineering: C 51: 226-232.

21.Jafari S, Singh Raman RK (2017) In-vitro biodegradation and corrosion-assisted cracking of a coated magnesium alloy in modified-simulated body fluid. Materials Science \& Engineering: C 78: 278-287.

22. Harandi SE, Banerjee PC, Easton CD, Singh Raman RK (2017) Influence of bovine serum albumin in Hanks' solution on the corrosion and stress corrosion cracking of a magnesium alloy. Mater Sci Eng C Mater Biol Appl 80: 335-345.

23.Bai H, He X, Ding P, Debao L, Minfang C (2019) Fabrication, microstructure, and properties of a biodegradable Mg-Zn-Ca clip. J Biomed Mater Res B Appl Biomater 107: 1741-1749.

24.Zhang $N$, Zhao D, Liu N, Yunfeng $W$, Jiahui $Y$, et al. (2018) Assessment of the degradation rates and effectiveness of different coated Mg-Zn-Ca alloy scaffolds for in vivo repair of critical-size bone defects. J Mater Sci Mater Med 29: 138.

25. Cipriano AF, Sallee A, Tayoba M, Mayra CCA, Alan L, et al. (2016) Cytocompatibility and early inflammatory response of human endothelial cells in direct culture with $\mathrm{Mg}-\mathrm{Zn}-\mathrm{Sr}$ alloys. Acta Biomaterialia 48: 499-250.

26.Wu Y, He G, Zhang Y, Yang L, Mei L, et al. (2016) Unique antitumor property of the Mg-Ca-Sr alloys with addition of Zn. Scientific Reports 6: 21736.

27.Song L, Wang LL, Ning L, Fan SW, Zhao X, et al. (2018) A modification and validation of quantitative morphometry classification system for osteoporotic vertebral compressive fractures in mainland Chinese. Osteoporos Int 29: 2495-2504.

28. Robinson DE, van Staa TP, Dennison EM, Cyrus C, William GD (2018) The limitations of using simple definitions of glucocorticoid exposure to predict fracture risk: A cohort study. Bone 117: 83-90.

29. Hu ZS, Liu XL, Zhang YZ (2018) Comparison of proximal femoral geometry and risk factors between femoral neck fractures and femoral intertrochanteric fractures in an elderly chinese population. Chin Med J (Engl) 131: 2524-2530.

30.Linsheng L, Guoxiang L, Lihui L (2016) Research on the preparation, biocompatibility and bioactivity of magnesium matrix hydroxyapatite composite material. Biomed Mater Eng 27: 251-258.

31.Rau JV, Antoniac I, Fosca M, Bonis AD, Blajan Al, et al. (2016) Glass-ceramic coated Mg-Ca alloys for biomedical implant applications. Materials Science \& Engineering: C 64: 362-369.

32.Carosio F, Ghanadpour M, Alongi J, Wågberg L (2018) Layer-by-layer-assembled chitosan/phosphorylated cellulose nanofibrils as a bio-based and flame protecting nano-exoskeleton on PU foams. Carbohydr Polym 202: 479-487.

33.Chen G, Ali F, Dong S, Zhonglin Y, Shuhong L, et al. (2018) Preparation, characterization and functional evaluation of chitosan-based films with zein coatings produced by cold plasma. Carbohydr Polym 202: 3946.

34.Yan T, Tan L, Xiong D, Xinjie L, Bingchun Z, et al. (2010) Fluoride treatment and in vitro corrosion behavior of an AZ31B magnesium alloy. Materials Science and Engineering: C 30: 740-748.

35. Wong HM, Yeung KW, Lam KO, VivianTam, Paul KC, et al. (2010) A biodegradable polymer-based coating to control the performance of magnesium alloy orthopaedic implants. Biomaterials 31: 2084-2096.

36. Muller $G$, Benkhai $H$, Matthes $R$, Birgit $F$, Wenke $F$, et al. (2014) Poly (hexamethylene biguanide) adsorption on hydrogen peroxide treated Ti-Al-V alloys and effects on wettability, antimicrobial efficacy, and cytotoxicity. Biomaterials 35: 5261-5277.

37. Huan ZG, Leeflang MA, Zhou J, Fratila-Apachitei LE, Duszczyk J (2010) In vitro degradation behavior and cytocompatibility of Mg-Zn-Zr alloys. J Mater Sci Mater Med 21: 2623-2635.

38.Gu X, Zhou W, Zheng Y, Limin D, Yulin X, et al. (2010) Microstructure, mechanical property, bio-corrosion 
and cytotoxicity evaluations of $\mathrm{Mg} / \mathrm{HA}$ composites. Materials Science and Engineering: C 30: 827-832.

39.Drynda A, Seibt J, Hassel T, Friedrich WB, Matthias P (2013) Biocompatibility of fluoride-coated magnesium-calcium alloys with optimized degradation kinetics in a subcutaneous mouse model. J Biomed Mater Res A 101: 33-43.

40.Kröger N, Kopp A, Staudt M, Mihaela R, Alexander $S$, et al. (2018) Hemocompatibility of plasma electrolytic oxidation (PEO) coated Mg-RE and Mg-Zn-Ca alloys for vascular scaffold applications. Materials Science and Engineering: C 92: 819-826.

41. Witte $F$ (2010) The history of biodegradable magnesium implants: A review. Acta Biomater 6: 16801692.

42.Seitz JM, Lucas A, Kirschner M (2016) Magnesium-based compression screws: A novelty in the clinical use of implants. JOM 68: 1177-1182.

43. Rahim MI, Weizbauer A, Evertz F, Andrea H, Manfred $R$, et al. (2017) Differential magnesium implant corrosion coat formation and contribution to bone bonding. J Biomed Mater Res A 105: 697-709.

44.Dou J, Chen Y, Chi Y, Huancai L, Guochao G, et al. (2017) Preparation and characterization of a calcium-phosphate-silicon coating on a Mg-Zn-Ca alloy via two-step micro-arc oxidation. Phys Chem Chem Phys 19: 15110-15119.

45.Kubásek J, Vojtěch D, Pospíšilová I, Michalcová A, Maixner J (2016) Microstructure and mechanical properties of the micrograined hypoeutectic $\mathrm{Zn}-\mathrm{Mg}$ alloy. International Journal of Minerals, Metallurgy, and Materials 23: 1167-1176.

46. Wan P, Tan L, Yang K (2016) Surface modification on biodegradable magnesium alloys as orthopedic implant materials to improve the bio-adaptability: A review. Journal of Materials Science \& Technology 32: 827-834.

47. Berglund IS, Jacobs BY, Allen KD, Stanley EK, Antonio $P$, et al. (2016) Peri-implant tissue response and biodegradation performance of a Mg-1.0 Ca-0.5 Sr alloy in rat tibia. Mater Sci Eng C Mater Biol Appl 62: 79-85.

48. Kubásek J, Vojtěch D, Jablonská E, Pospíšilová I, Lipov J, et al. (2016) Structure, mechanical characteristics and in vitro degradation, cytotoxicity, genotoxicity and mutagenicity of novel biodegradable $\mathrm{Zn}-\mathrm{Mg}$ alloys. Materials Science and Engineering: C 58: 24-35.

49.Griebel AJ, Schaffer JE, Hopkins TM, Alaa A, Tinomudaishe $M$, et al. (2018) An in vitro and in vivo characterization of fine WE43B magnesium wire with varied thermomechanical processing conditions. J Biomed Mater Res B Appl Biomater 106: 1987-1997.

50. Henderson HB, Ramaswamy V, Wilson-Heid AE, Michael SK, Josephine BA, et al. (2018) Mechanical and degradation property improvement in a biocompatible Mg-Ca-Sr alloy by thermomechanical processing. Journal of the Mechanical Behavior of Biomedical Materials 80: 285-292.

51.Yusa K, Yamamoto O, lino M, Hiroshi T, Masayuki F, et al. (2016) Eluted zinc ions stimulate osteoblast differentiation and mineralization in human dental pulp stem cells for bone tissue engineering. Archives of Oral Biology 71: 162-169.

52.Tan J, Nie E, Zhang C, Jiang R (2016) Effect of zinc ion on the expression of osteoblastic proteins in MC3T3-E1 cells in inflammatory environment. Chinese Journal of Stomatology 51: 486-490.

53.Yuan Q, Huang Y, Liu D, Chen M (2018) Effects of solidification cooling rate on the corrosion resistance of a biodegradable $\beta$-TCP/Mg-Zn-Ca composite. Bioelectrochemistry 124: 93-104.

54.Yang X, Xu S, Chen X, He D, Ke X, et al. (2017) Intra-bone marrow injection of trace elements codoped calcium phosphate microparticles for the treatment of osteoporotic rat. J Biomed Mater Res A 105: 1422-1432.

55.Zhao M, Dai Y, Li X, Yang L, Ying Z, et al. (2018) Evaluation of long-term biocompatibility and osteogenic differentiation of graphene nanosheet doped calcium phosphate-chitosan AZ91D composites. Materials Science and Engineering: C 90: 365-378. 